\title{
Influences of social learning on mate-choice decisions
}

\author{
DAVID J. WHITE \\ Indiana University, Bloomington, Indiana
}

\begin{abstract}
Evidence from both field and laboratory is consistent with the hypothesis that animals can acquire mate preferences by observing the mating behavior of others. It is difficult, however, to distinguish social learning about mates from a host of other social effects on mating that do not produce changes in preferences. Examples are drawn from laboratory studies on mate choice in female and male Japanese quail that illustrate ways in which social cues influence mating decisions. Quail of both sexes use social cues to modify their mate choices, but the sexes use the information to serve different purposes. Female quail gain preferences for males seen mating with other females, whereas males avoid females that they had observed mating with other males. This sex difference in social learning provides an example of how costs and benefits of sexual behavior can shape decision-making processes. Implications of the influence of social learning on sexual selection are briefly discussed.
\end{abstract}

Assessing and choosing among potential mates can be a demanding task, requiring acquisition and processing of a wide variety of information about mate quality. For example, static traits of potential mates, such as coloration, body size, song quality, or scent, can be evaluated against innate preferences (Andersson \& Iwasa, 1996; Bateson, 1983; Collins, Hubbard, \& Houtman, 1994; Gibson \& Langen, 1996; Gould \& Gould, 1997; Houde, 1997; Jennions, Blackwell, \& Passmore, 1995; Jennions \& Petrie, 1997; Witte \& Ryan, 1998). Behavioral cues, such as courtship vigor, winning intrasexual contests, acquiring territory or nuptial gifts, or engaging in parental care, may play a role in mate choice (Alatalo, Lundberg, \& Glynn, 1986; Deutsch \& Nefdt, 1992; Horne \& Ylönen, 1996; Mennill, Ratcliffe, \& Boag, 2002; Schwagmeyer \& Mock, 2003; Thornhill, 1976; Vinnedge \& Verrell, 1998). In addition, demographic and life history factors, such as the number of potential mates available, the costs of searching for a mate, and the age and past mating history of the chooser, may affect mate selection (Gibson \& Bachman, 1992; Janetos, 1980; Kodric-Brown \& Nicoletto, 2001; Real, 1991; Riebel, 2000; Wiegman, Real, Capone, \& Ellner, 1996).

Environmental factors - for example, ambient color, temperature and lighting, predation, food availability, seasonal timing, or climatic events - can also influence mate selection and reproductive behavior (Badyaev \&

I was supported by NSF Grant 0234047 during the writing of this paper. I thank Jeff Galef for the invitation to write a review for this issue as well as for his thoughtful comments on an earlier draft of the manuscript. Julie Gros-Louis and an anonymous reviewer also provided valuable comments on an earlier draft. Correspondence concerning this article should be addressed to D. J. White, Department of Psychology, University of Pennsylvania, 3815 Walnut St., Philadelphia, PA 19104 (e-mail: whitedj@psych.upenn.edu).
Martin, 2000; Blackwell \& Passmore, 1996; Endler, 1991; Heindl \& Winkler, 2003; Magnhagen, 1991; Roitberg, Sircom, Roitberg, Van Alphen, \& Mangel, 1983; Sullivan, 1994). In some cases, factors used to judge males, such as local song dialects or courtship strategies used, are particular to the local environment (Baptista \& Trail, 1992; Freeberg, 2000; Reynolds, Gross, \& Coombs, 1993). All of these factors may interact to determine the best potential mate in any given context. For example, bright males may enjoy enhanced reproductive success in some contexts, whereas in other contexts (e.g., under predation risk), drab (less conspicuous) males may be favored (Godin \& Briggs, 1996; Gong \& Gibson, 1996).

One means of managing all this information and filtering out the unimportant from the critical is to learn about potential mates by observing the behavior of others. If interacting with more knowledgeable conspecifics can shape preferences, then naive individuals can develop mate choice behavior that is locally adaptive. Indeed, there are many examples of social experience structuring mate preferences. From very early in life, young can learn aspects of their sex and species from interactions with parents and siblings (Bateson, 1978; Gallagher, 1976; Slagsvold, Hansen, Johannessen, \& Lifjeld, 2002). Also, throughout development, interactions with conspecifics can shape later mating preferences and mating behavior (Freeberg, Duncan, Kast, \& Enstrom, 1999; Riebel, 2000; West \& King, 1988; White, King, \& West, 2002).

The focus of this review will be on immediate effects of social context on mating preferences-specifically, on whether individuals can benefit from observing the matechoice decisions of others. By copying a conspecific's mate choice, the copier can select a mate of no worse quality than did the chooser. In addition, copying females avoid all costs associated with independently searching 
for and assessing mates (Brooks, 1998; Dugatkin, 1996; Gibson \& Höglund, 1992; Kraak, 1996; Losey, Stanton, Telecky, Tyler, \& the Zoology 691 Graduate Seminar, 1986; Nordell \& Valone, 1998; Pruett-Jones, 1992).

\section{Theory}

Several theoretical models have been used to investigate how socially influenced (nonindependent) mate choice may affect assortative mating and sexual selection (Agrawal, 2001; Gibson \& Höglund, 1992; Kirkpatrick \& Dugatkin, 1994; Laland, 1994; Losey et al., 1986; Pruett-Jones, 1992; Servedio \& Kirkpatrick, 1996; Sirot, 2001; Stöhr, 1998; Wade \& Pruett-Jones, 1990). Results suggest that, depending on the underlying economics of why animals are socially influenced, intensity of sexual selection can be increased, decreased, or left unchanged by nonindependent mate choice. If, for example, females copy other females as a strategy to avoid the costs of searching for a mate, then selection pressure on males can be reduced by female mate-choice copying because fewer females are independently assessing male quality and the success of high-quality males will be dependent on the ability of choosers to discriminate among males.

Alternatively, if females copy others to learn about the quality of males, mate-choice copying could increase selection pressure on male traits. In such cases, female preferences would become concordant, increasing variance in male mating success. As a result, a minority of males would garner the majority of matings.

Some social effects on mate choice may appear to be a result of nonindependent choice, but are not. For example, a male's attractiveness may increase as a result of his mating with one female due to his increased courtship vigor. Other observing females may select such a male, but each one's choice would be based on her own independent preferences for his display (Grant \& Green, 1996; Slagsvold \& Viljugrein, 1999). In other cases, females may have a tendency to aggregate and travel in groups (conspecific cuing; Kiester, 1979). Such social movement could lead to many matings for a male in an area visited by an aggregation of females, but, again, there would be no modification of females' preferences (McComb \& Clutton-Brock, 1999; Shuster \& Wade, 1991).

\section{Empirical Support}

In the field, evidence of social factors affecting mate choice comes predominantly from research on lekking species. In lekking animals, groups of females visit mating areas occupied by many courting males. The common feature of lekking species is high variance in male reproductive success, driven by high concordance in female choice (Bradbury \& Gibson, 1983; Bradbury, Vehrencamp, \& Gibson, 1985; Höglund \& Alatalo, 1995). Leks thus provide an excellent venue for looking for social influences on mate choice decisions; females have the opportunity to observe the mate choices of others and choose similarly. Field experiments suggest that mate-choice copying may occur in some lekking species but not in others (Clutton-Brock, Hiraiwa-Hasegawa, \& Robertson, 1989; Dugatkin \& Höglund, 1995; Gibson, 1992; Gibson, Bradbury, \& Vehrencamp, 1991; Lill, 1974; McComb \& Clutton-Brock, 1999). Lack of experimental control often makes it impossible to determine for certain what factors are responsible for any observed skew in mating success.

Laboratory preparations make it possible to examine the stimulus control of mate-choice decisions, although they sacrifice some ecological validity. Dugatkin and collaborators conducted a series of studies of mate-choice copying in Trinidadian guppies (Poecilia reticulata; see also Goldschmidt, Bakker, \& Feuth-de Bruijn, 1993; Grant \& Green, 1996; Schlupp, Marler, \& Ryan, 1994; Shuster \& Wade, 1991; Witte \& Ryan, 1998, for work in other aquatic species). Dugatkin (1992; Dugatkin \& Godin, 1992) gave focal female guppies the opportunity to view two target males in end chambers of an aquarium. A model female was placed in one of the male's chambers so that the focal female could view him courting and copulating with a female, whereas the other male was alone. Significantly more focal females than expected by chance spent the majority of their time nearer the male observed copulating with the model female. The observed bias in females' choices could not be explained by a tendency to school near a group or in an area where other females had been seen or to choose the male as a result of his increased courtship vigor.

Dugatkin used fish that were first-generation descendants of wild populationsfrom the Quaré and Turure Rivers in Trinidad. Recent evidence has revealed that mate-choice copying in guppies may not generalize across populations. Lafleur, Lozano, and Sclafani (1997) failed to find evidence of mate-choice copying in domestic lines of guppies, and Brooks (1996) failed to find mate-choice copying in a feral population from South Africa. In fact, Brooks (1999) reported an opposite effect in an Australian population: that focal females spend less time near a male seen courting a female. The reason for the discrepancy in female guppy mate choice is not clear. Possibly, across populations different ecological factors exist that vary the advantage of mate-choice copying (Dugatkin, 1998).

If female guppies copy the mate choices of others, why do they do so? Dugatkin and Godin (1993) provided some support for the hypothesis that females use matechoice copying as a strategy for learning mate preferences. They investigated the intensity of mate-choice copying among guppies of different ages, reasoning that if matechoice copying were used by naive females to learn to choose quality mates, then younger females would benefit more from copying older, more experienced females than vice versa. They found that smaller (assumed to be younger) females copied the mate choices of larger (assumed to be older) female models more readily than larger females copied the mate choices of smaller females.

Dugatkin and Godin (1998) attempted to determine if changing costs associated with mate choice might influ- 
ence mate-choice copying. To do so, they tested focal females that had been food restricted, hypothesizing that it would be more costly for such females to expend energy in searching for and assessing a mate. Hungry females did not, however, show an enhanced tendency to copy other females' mate choices. In fact, contrary to the hypothesis, they showed a decreased tendency to matechoice copy, possibly because females do not engage in mate choice when hungry. Currently therefore, there is little empirical evidence in support of the avoidance-ofsearch-costs explanation of mate-choice copying (see also Briggs, Godin, \& Dugatkin, 1996).

\section{MATE CHOICE IN FEMALE JAPANESE QUAIL}

Here, I describe a research preparation designed to aid in the understanding of the role of social learning in mate choice in an avian species, the Japanese quail (Coturnix japonica). Of particular interest is whether social cues impact mate choice and mate preferences in quail, what is learned socially about potential mates, and, finally, what stimuli control such effects.

\section{Natural History}

The Japanese quail is a popular model species for studying sexual behavior due to the year-round willingness of quail to engage in sex and their robustness in laboratory environments (Mills, Crawford, Domjan, \& Faure, 1997). Unfortunately, quail are less popular as subjects of field studies. The few reports of the mating behavior of Japanese quail in natural or seminatural environments suggest that both sexes engage in mate choice (Mills et al., 1997; Nichols, 1991). Males actively pursue and attempt to mount females, whereas females engage in mate choice by regulating proximity to males. Quail mate either monogamously or with some degree of polygamy. Within a breeding season, mate switching and extrapair copulations occur and females can lay multiple clutches
(Nichols, 1991). Males provide little to no parental care (Domjan \& Hall, 1986b; Hess, Petrovich, \& Goodwin, 1976; Mills et al., 1997; Nichols, 1991).

\section{Female Mate Choice: Enhancement of Preferences}

Galef and White (1998) studied whether social factors could influence the mate choices of female Japanese quail. The procedure was similar to that of the guppy experiments described above. A focal female quail was given a 10-min pretest during which she could affiliate with two males held in the end chambers of a mate choice apparatus(Figure 1). For the next $10 \mathrm{~min}$, the focal female, held in the center of the apparatus, saw a model female mate with the male with which the focal female had spent the minority of time nearer during the pretest (her nonpreferred male). After the model female had been removed, the focal female had a 10-min posttest during which she could once again affiliate with the two males. The difference in the amount of time focal females spent with their initially nonpreferred males was calculated. Thus, each female served as her own control.

Focal females consistently showed a significant increase in the time they spent affiliating with males seen mating with model females (Figure 2; Galef \& White, 1998). In contrast, females having no opportunity to observe a model female mate with their nonpreferred males remained consistent from pretest to posttest in the amount of time they spent affiliating with the two males. Focal females spent a mean of $2.21( \pm 0.40)$ min with their nonpreferred males in the pretest, and increased the time they spent with those males to a mean of $5.22( \pm 0.70) \mathrm{min}$ in the posttest. This increase in the time focal females spent with their nonpreferred males after seeing them mate with another female has been remarkably consistent and has now been replicated in different laboratories (e.g., Akins, Levens, \& Bakondy, 2002). Recent results suggest that focal females will modify their preferences for nonpreferred males after seeing video images of

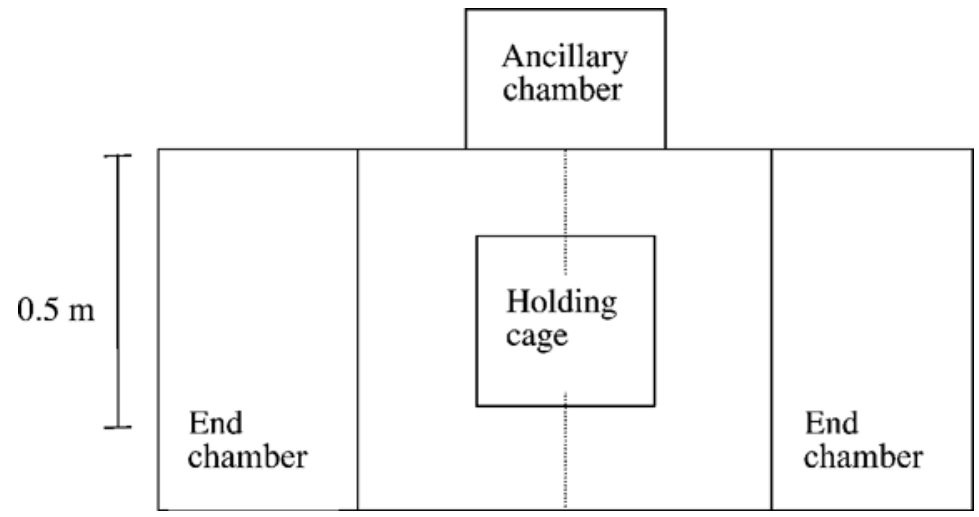

Figure 1. Scale depiction of mate choice apparatus used to test female and male quail in Galef and White (1998) and White and Galef (1999a, 1999b, 1999c, 2000a, 2000b). 


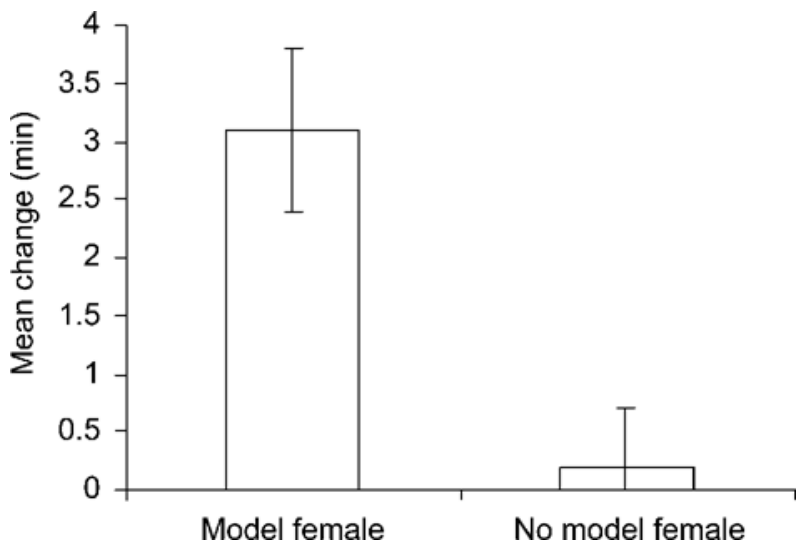

Figure 2. Mean change from pretest to posttest in the time focal females spent with the initially nonpreferred male in conditions in which the focal females observed a model female with the nonpreferred male during the observation phase (model female; $N=$ 13) and in which the focal females did not observe a model female during the observation phase (no model female; $N=11$ ). Data are taken from Galef and White (1998). Bars represent $\pm 1 S E M$.

model females mating with their nonpreferred males (Ophir \& Galef, 2003a), or when presented with static, taxidermically prepared model females positioned near nonpreferred males (Akins et al., 2002).

\section{Stimulus Control of Mate Choice}

Although the results described above are consistent with the hypothesis that female preferences are modified as a result of social experience, there are a number of alternative hypotheses that could potentially explain the findings. First, focal females could be choosing independently, spending more time with the nonpreferred male after he mated because he had become more attractive while courting and copulating with the model. Alternatively, focal females could be moving into an area where they had recently seen another female. In the latter case, an area, rather than male, had become more attractive to focal females in the posttest. Furthermore, the amount of time a female spends near a male may not reflect her desire to mate with that male.

Galef and White (1998; White \& Galef, 1999b) conducted a series of experiments to differentiate among the various possibilities. To determine whether males changed as a result of the interaction with a model female, Galef and White (1998) blocked focal females' view of the interaction between the model female and the male. They found that females had to observe the interaction between a male and a model female to change their behavior toward their nonpreferred males. But what part of the interaction between the male and the model female was most important in changing the focal females' affiliative preferences? White and Galef (1999b) separated model females from nonpreferred males with either a transparent or an opaque Plexiglas barrier. The model females and males could not copulate, but in various conditions the focal females could see (1) both a model female and a courting male, (2) a model female and a male standing beside her but not courting, or (3) a courting male but not the model female he was courting. Focal females increased the time they spent affiliating with their nonpreferred males only in the first two cases, when model females could be seen. Whether or not the male courted was irrelevant.

These data suggest that observation of a female is a critical stimulus for focal females to modify their affiliative behavior. When White and Galef (1999b) used a male instead of a female as a model, focal females did not increase the time they spent affiliating with their nonpreferred males. Thus, the increase in time focal females spent near their nonpreferred males was not a result of the focal females' going to an area where more birds had been seen. It was possible, however, that focal females were moving toward an area where other females had been seen, whether or not males were in the area (see Kiester, 1979). By reversing the locations of the two males after the focal female had observed the model and one of the males interact, White and Galef (1999b) tested whether focal females were attracted to the location where a male and a female had been seen or to the nonpreferred male per se. After reversal of the locations of the males, females increased the time they spent near the nonpreferred male even when he was in the new location. Thus, females were attending to the cues produced by other females and changing their behavior toward males as a result.

The finding that focal females did not need to see the model and male mate or even court may raise questions as to whether this is a true case of mate-choice copying (Pruett-Jones, 1992). If the definition of mate-choice copying requires copying of the actual act of mating, then the change in female quail's preferences described above is not mate-choice copying. If, however, the definition of mate-choice copying requires only that females copy the mate choices of other females, then the quail result is a case of mate-choice copying.

To an observing focal quail, close proximity between a male and a female is probably a reliable indicator of mate choice. Given that male Japanese quail are so sexually aggressive, in the wild a female standing within $20 \mathrm{~cm}$ of a male for $10 \mathrm{~min}$ would most likely be mounted or would have copulated recently with that male (see Domjan \& Hall, 1986a; Nichols, 1991). Thus, female quail do seem to be copying the mate choices of other females, if not their actual mating behavior.

\section{Validating the Measures}

I have discussed social influences on female affiliative preferences in terms of focal females' preferred and nonpreferred males, yet the possibility exists that the time that a female spends affiliating with a male is not a valid measure of her intention to mate with him. The de- 
sign of the mate-choice test used with quail is similar to that of tests commonly used to examine mate choice in many other species. The advantage of this preparation is that it allows female choice to be isolated from male coercion. However, the validity of the proxy measure is tested only in a few studies in which time spent near a conspecific of the opposite sex is used as the proxy measure for sexual preference. White and Galef (1999a) determined whether time spent by a female quail near a male was a predictor of her preference to mate with that male. To do so, White and Galef (1999a) harnessed males on tethers in their end chambers. With the partitions removed so that the end chambers were not separated from the central choice arena, females could approach and solicit copulations from the tethered males or remain out of their reach. The females had $10 \mathrm{~min}$ to affiliate near two males in end chambers with partitions in place, and then, when the partitions were removed, they had 10 min to copulate with them. When given the opportunity to copulate, the females copulated first, last, and more often with the male with which they had spent the majority of time in the preceding affiliation test (White \& Galef, 1999a).

\section{Trait Copying}

If the females were learning about the qualities of males by observing other females, what qualities of the males were they learning about? White and Galef (2000a) determined whether females could gain generalizable preferences for traits of males seen mating. In order for mate-choice copying to influence the evolution of male sexually selected traits, females must gain a preference not only for an individual seen mating, but also for that male's traits. In other words, a socially enhanced preference would have to generalize to an enhanced preference for other males sharing the characteristics of the male seen mating (Agrawal, 2001; Kirkpatrick \& Dugatkin, 1994).

To test this idea, White and Galef (2000a) took advantage of information concerning color mutations in quail. Single-locus random mutations that influence plumage coloration occur in Japanese quail (Cheng \& Kimura, 1990). For example, a mutation can produce three white primary feathers on the wings. White and Galef (2000a) created "pseudomutant" quail by giving them a distinct feather-color trait: three white feathers attached to their crowns. Although this trait does not exist in nature, it is similar enough to real color mutations that it could reasonably evolve through a singlelocus mutation. White and Galef (2000a) then used the pseudomutants in a mate-choice copying preparation similar to that of the experiments described above. Here, focal females observed a pseudomutant male mating with a model female in the ancillary chamber of the apparatus (Figure 1) and then chose between a different pseudomutant male and a normal male in the end chambers. Only females that had observed the pseudomutant male mating showed an enhanced preference for other pseudomutant males during the preference test.

\section{Learning About Behavior}

In addition to providing information about the morphological traits of males, recent research has revealed that females may use social information to learn about males' aggressive behavior. Male Japanese quail can be highly aggressive with conspecific males and can force copulations upon females. Ophir and Galef (2003b) have shown that females that observe aggressive encounters between males subsequently spend more time near the losers of those encounters than near the winners. These results are contrary to results from other species, which showed that winners of aggressive contests are often preferred as mates (Mennill et al., 2002; Otter et al., 1999) and suggested that females may be influenced by observing the mating behavior of others for reasons other than mate selection-for example, to reduce the chances of attack by an aggressive male (Persaud \& Galef, 2003).

In sum, results of female mate-choice experiments have revealed that (1) female quail modify their preferences to mate with males seen mating, (2) culturally established preferences can generalize to other males with similar traits, and (3) females can use social cues to assess males' aggressiveness.

\section{MATE CHOICE IN MALE JAPANESE QUAIL}

Mate choice by males has received far less attention than that by females. Since, in most cases, the costs of reproduction incurred by males are less than those incurred by females, the need to make a good choice is greater for females than for males. Theory thus suggests that males can benefit from mating as often as possible without being discriminating in their choice of partners, whereas females benefit from mating selectively with a highquality partner (Trivers, 1972). Since the costs and benefits of mating differ for males and for females, a comparison of how social factors influence male and female mate choices may provide some insights into how sexual selection may have shaped mating decision processes.

What factors are important to males in making matechoice decisions? One possible answer is nothing; because the costs of reproductive failure are low for males, males should mate unselectively whenever an opportunity presents itself. There are, however, costs associated with mating borne only by males. First, in species in which there is high variance in mating success, for the majority of males the opportunity costs of failing to mate successfully on any given occasion may be substantial because most males may get only a few mating opportunities. Also, males do not have the assurance of parentage that females have; thus, males engaging in parental care can be at risk of cuckoldry (Erickson \& Zenone, 1976). In addition, males may face attacks from other males during competition over mates. It could therefore be costly for a male to mate with a female that had recently mated with another male; she may be less likely to be fertilized by the second male due to sperm competition, she may be more likely to cuckold the second male, and 
there may be an aggressive male nearby. These factors suggest that when given the opportunity to choose between two females, males would use social information in the opposite way that females do-that is, they should prefer the unmated (more likely to be fertilized) female.

\section{Male Mate Choice: Reversal of Preference}

Using a preparation similar to that used in their female mate-choice experiments, White and Galef (1999c) determined whether focal males that had observed an initially preferred female mate with another male would subsequently find her less attractive. The results are presented in Figure 3. Focal males reliably reduced the amount of time that they spent near females after seeing them copulate with a model male. Once again, several possible hypotheses can explain this finding. First, focal males may be using the past mating history of females to choose the one most likely to be fertilized. Alternatively, focal males may respond to behavioral cues of receptive females, and females may be less interested in another male after recently mating. Also, due to the increased risk of aggression, focal males may avoid an area where another male was seen or may avoid a female that is the pair mate of another. Finally, tests of affiliative preferences may not provide a valid measure of male mate choice.

\section{Stimulus Control of Mate Choice}

White and Galef (1999c) undertook a series of experiments to identify the stimuli critical for influencing the behavior of focal males. The results suggested that (1) the model male and the female had to be observed interacting by the focal male, (2) the focal male had to see the model male court the female (but not necessarily copulate with her), and (3) the focal male decreased the time he spent with a female he had seen courted, not the

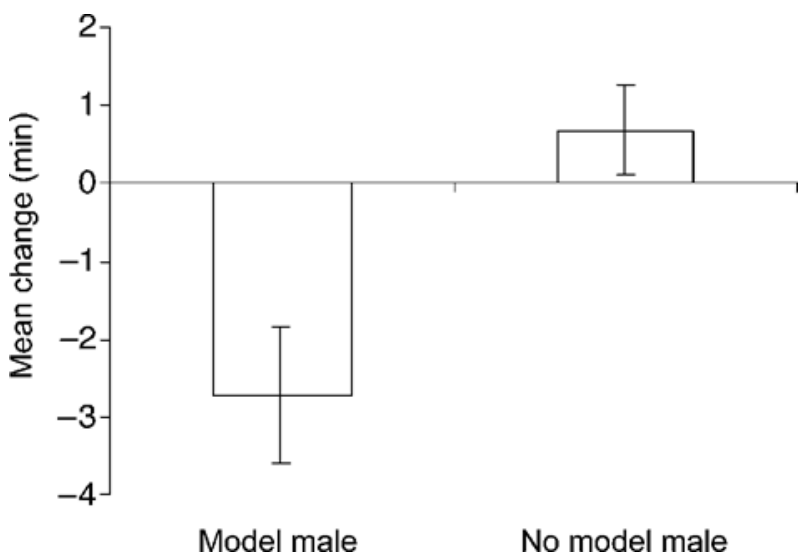

Figure 3. Mean change from pretest to posttest in the time focal males spent with the initially preferred female in conditions in which the focal males observed a model male with the preferred female during the observation phase (model male; $N=15$ ) and in which the focal males did not observe a model male during the observation phase (no model male; $N=15$ ). Data are taken from White and Galef (1999c). Bars represent $\pm 1 S E M$. time he spent in an area where he had seen a model male. Taken together, the results are consistent with the view that males attend to the mating history of females and prefer females that they had not seen courted by other males.

White and Galef (1999a) also determined whether the dependent measure time spent near a female predicted a male's probability of mating with her. After taking a 10 -min measure of focal males' affiliative preferences for two females restrained in end chambers of the apparatus (Figure 1), White and Galef (1999a) removed barriers separating the target females from the central area, thus giving focal males $10 \mathrm{~min}$ to pursue females and mate with them. The males were surprisingly selective; they rarely copulated with more than one of the females during a trial. The majority of males copulated first, last, and more often with the female they had spent the majority of time near in the previous test of affiliation.

Ruscio and Adkins-Regan (2003) have recently shown a similar social effect on males' mate choices. To provide information about reproductive quality of females, instead of using a model male, Ruscio and AdkinsRegan placed quail chicks in the end chamber with one female. Focal males spent significantly more time near the female without chicks than near the female with chicks. This result is concordant with White and Galef's (1999c) finding that males choose females that are less likely to be paired and, consequently, more likely to be fertilizable.

\section{Sex Differences in Duration of Effects}

If differences between sexes in their response to observing potential mates mating with conspecifics were based on females' acquiring information about the quality of potential mates and males' acquiring information about the fertilizability of potential mates, then there should be differences not only in the direction of responses by the two sexes, but also in the duration of social effects on mate choice. For females, information acquired about a male's quality would remain valuable in the future. For males, however, the information acquired from observing a female mating would become less valuable over time, because a prior male's reproductive advantage would be reduced as time progresses (Birkhead \& Biggins, 1997). To test this hypothesis, White and Galef (2000b) conducted tests on both focal females and focal males that involved a 2-day delay between the time when a focal subject observed a model interacting with a potential mate and the time of test of affiliative preference. Females showed an enhanced preference for a male seen mating with a model female 2 days earlier. However, after 2 days (the time, in other Phasianadae, after which first male precedence in sperm competition gives way to last male advantage; Birkhead, Wishart, \& Biggins, 1995), males no longer showed a decrease in their preference for a female seen mating with a model male. In fact, after 2 days, focal males showed an increased preference for a target female that they had seen mating. This suggests that the benefits females attain 
from copying the mate choice of others may also be present for males, but they are outweighed by the short-term reduction in the probability of fertilizing a female seen mating with another.

\section{CONCLUSION}

Social factors from infancy into adulthood can play a significant role in modifying and shaping mate choices. As work with quail shows, information received by observing the mate choices of others can be multifaceted. Females can acquire preferences for males seen mating (Galef \& White, 1998; White \& Galef, 1999b) or for traits of those males (White \& Galef, 2000a), and they can learn about behavioral characteristics of the males (Ophir \& Galef, 2003b) as well as where females may be (White \& Galef, 1999b). Males, in comparison, use similar information for a different purpose: to determine the likelihood of fertilization of a potential mate (White \& Galef, 1999c).

Studying mate choice in the laboratory provides control over what subjects can observe when assessing potential mates, leading to confidence about the role social stimuli play in influencing mate choice that has not yet been achieved in the field. The loss of ecological validity inherent in laboratory work, however, can be an important concern (see Crews \& Moore, 1986; W. E. Wagner, 1998). The mate choice apparatus used in many laboratory studies forces animals to make mate choice decisions on the schedule of the experimenter, and the assumptions that animals are actually choosing a mate, or choosing a mate as they would in the wild, are often not tested. Laboratory tests of mate choice need to be functionally validated in more complex settings, in which animals have greater freedom to interact with conspecifics and choose or not choose mates. Compromises between ecologically limited conditions in the lab and uncontrolled conditions in the field do exist (see Freeberg, 2004). If patterns seen in the laboratory reveal truly important mechanisms of mate choice, they should be found in less rigidly controlled settings as well.

Mate-choice copying has been investigated in many species, with mixed results (see Galef \& White, 2000). This should come as no surprise, given the wide variety of factors important for mate-choice decisions depending on an animal's life history, mating system, or particular context. For example, there is growing evidence that females in some species show preferences for mates that are genetically compatible with them (Bateson, 1978; Penn, 2002). In such cases, another female's mate choice would not provide useful information to an observing female about the compatibility of that male as a mate. Looking for mechanisms such as mate-choice copying across species without taking into account how social information may interact with ecological and life-history variables is unlikely to lead to an understanding of the utility of nonindependent mate choice.

Although I have focused here on how sexual preferences may be modified by social learning, mate-choice copying is not the sole social effect on mating that has evolutionary consequences (R. H. Wagner \& Danchin, 2003; West-Eberhard, 1983; Westneat, Walters, McCarthy, Hatch, \& Hein, 2000). Because mating is a social activity in sexually reproducing species, social information surrounding mating is ubiquitous. Thus, the opportunities are widespread for various types of social information to influence animals' traits, behaviors, and decisions. Even if social interactions do not lead to changes in mate preferences, they may still play a role in affecting selection pressures on a host of traits and characteristics. For example, conspecific cuing may favor selection acting on males' ability to hold harems or popular territories. The evolutionary consequences of mate-choice copying have been studied extensively, whereas the role of other social effects in shaping behavior, development, cognition, and social structure has not. Understanding how social behavior and social learning can impact reproductive choices is rich with possibilities for theoretical analysis and for both laboratory-based and fieldbased research.

\section{REFERENCES}

AgrawAL, A. F. (2001). The evolutionary consequences of copying male traits. Behavioral Ecology \& Sociobiology, 51, 33-40.

AKIns, C. K., LEVEns, N., \& BAKOndy, H. (2002). The role of static features of males in the mate choice behavior of female Japanese quail (Coturnix japonica). Behavioural Processes, 58, 97-103.

Alatalo, R. V., Lundberg, A., \& Glynn, C. (1986). Female pied flycatchers choose territory quality and not male characteristics. Nature, 323, 152-153.

Andersson, M., \& IWASA, Y. (1996). Sexual selection. Trends in Ecology \& Evolution, 11, 53-58.

BADYAEV, A. V., \& MARTIN, T. E. (2000). Sexual dimorphism in relation to current selection in the house finch. Evolution, 54, 987-997.

Baptista, L. F., \& Trail, P. W. (1992). The role of song in the evolution of passerine diversity. Systematic Biology, 41, 242-247.

BAtESON, P. (1978). Sexual imprinting and optimal outbreeding. $\mathrm{Na}$ ture, 273, 659-660.

Bateson, P. (1983). Mate choice. Cambridge: Cambridge University Press.

BirkHEAD, T. R., \& Biggins, J. D. (1997). Sperm competition mechanisms in birds: Models and data. Behavioral Ecology, 9, 253-260.

BirkHEAD, T. R., Wishart, G. J., \& BigGins, J. D. (1995). Sperm precedence in the domestic fowl. Proceedings of the Royal Society of London: Series B, 261, 285-292.

BlackWE Ll, P. R. Y., \& PASSMORE, N. I. (1996). Time constraints and multiple choice criteria in the sampling behavior and mate choice of the fiddler crab, Uca annupiles. Behavioral Ecology \& Sociobiology, 38, 407-416.

Bradbury, J. W., \& GIBSON, R. M. (1983). Leks and mate choice. In P. Bateson (Ed.), Mate choice (pp. 109-140). Cambridge: Cambridge University Press.

Bradbury, J. W., Vehrencamp, S. L., \& Gibson, R. M. (1985). Leks and the unanimity of female choice. In P. J. Greenwood, P. H. Harvey, \& M. Slatkin (Eds.), Evolution: Essays in honour of John Maynard Smith (pp. 301-314). Cambridge: Cambridge University Press.

Briggs, S. E., Godin, J.-G. J., \& Dugat Kin, L. A. (1996). Mate-choice copying under predation risk in the guppy (Poecilia reticulata). Behavioral Ecology, 7, 151-157.

Brooks, R. (1996). Copying and the repeatability of mate choice. Behavioral Ecology \& Sociobiology, 39, 323-329.

Brooks, R. (1998). The importance of mate copying and cultural inheritance of mating preferences. Trends in Ecology \& Evolution, 13, 45-46. 
Brooks, R. (1999). Mate choice copying in guppies: Females avoid the place where they saw courtship. Behaviour, 136, 411-421.

Cheng, K. M., \& KimurA, M. (1990). Mutations and major variants in Japanese quail. In R. D. Crawford (Ed.), Poultry breeding and genetics: Developments in animal and veterinary sciences (pp. 333-362). Amsterdam: Elsevier.

Clutton-Brock, T. H., Hiraiwa-Hasegawa, M., \& Robertson, A. (1989). Mate choice on fallow deer leks. Nature, 340, 463-465.

Collins, S. A., Hubbard, C., \& Houtman, A. M. (1994). Female mate choice in zebra finches: The effect of male beak color and male song Behavioral Ecology \& Sociobiology, 35, 21-25.

Crews, D., \& Moore, M. C. (1986). Evolution of mechanisms controlling mating behavior. Science, 231, 121-125.

Deutsch, J. C., \& NeFDT, R. J. C. (1992). Olfactory cues influence female choice in two lek-breeding antelopes. Nature, 356, 596-598

DOMJAN, M., \& HALL, S. (1986a). Determinants of social proximity in Japanese quail (Coturnix coturnix japonica): Male behavior. Journal of Comparative Psychology, 100, 59-67.

Domjan, M., \& Hall, S. (1986b). Sexual dimorphism in the social proximity behavior of Japanese quail (Coturnix coturnix japonica) Journal of Comparative Psychology, 100, 68-71.

DugatKin, L. A. (1992). Sexual selection and imitation: Females copy the mate choice of others. American Naturalist, 139, 1384-1389.

Dugatkin, L. A. (1996). Copying and mate choice. In C. M. Heyes \& B. G. Galef, Jr. (Eds.), Social learning in animals: The roots of culture (pp. 85-106). San Diego: Academic Press.

DUGATKIN, L. A. (1998). A comment on Lafleur et al.'s re-evaluation of mate-choice copying in guppies. Animal Behaviour, 56, 513-514.

Dugatkin, L. A., \& Godin, J.-G. J. (1992). Reversal of female mate choice by copying in the guppy (Poecilia reticulata). Proceedings of the Royal Society of London: Series B, 249, 179-184.

Dugatkin, L. A., \& Godin, J.-G. J. (1993). Female mate copying in the guppy (Poecilia reticulata): Age-dependent effects. Behavioral Ecology, 4, 289-292.

DugATKIn, L. A., \& Godin, J.-G. J. (1998). Effects of hunger on matechoice copying in the guppy. American Naturalist, 104, 194-202.

DugATKIN, L. A., \& HöGLUnD, J. (1995). Delayed breeding and the evolution of mate copying in lekking species. Journal of Theoretical Biology, 174, 261-267.

ENDLER, J. A. (1991). Variation in the appearance of guppy color patterns to guppies and their predators under different visual conditions. Vision Research, 31, 587-608.

ERICKSON, C. J., \& ZENONE, P. G. (1976).Courtship differences in male ring doves: Avoidance of cuckoldry? Science, 192, 1353-1354.

FREEBERG, T. M. (2000). Culture and courtship in vertebrates: A review of social learning and transmission of courtship systems and mating patterns. Behavioural Processes, 51, 177-192.

FREEBERG, T. M. (2004). Social transmission of courtship behavior and mating preferences in brown-headed cowbirds, Molothrus ater. Learning \& Behavior, 32, 122-130.

Freeberg, T. M., Duncan, S. D., Kast, T. L., \& Enstrom, D. A. (1999). Cultural influences on female mate choice: An experimental test in cowbirds, Molothrus ater. Animal Behaviour, 57, 421-426.

GALEF, B. G., JR., \& WHITE, D. J. (1998). Mate-choice copying in Japanese quail, Coturnix coturnix japonica. Animal Behaviour, 55, 545552.

GALEF, B. G., JR., \& WHITE, D. J. (2000). Evidence of social effects on mate choice in vertebrates. Behavioural Processes, 51, 167-175.

Gallagher, J. E. (1976). Sexual imprinting: Effects of various regimens of social experience on mate preference in Japanese quail, Coturnix coturnix japonica. Behaviour, 57, 91-115.

GIBSON, R. M. (1992). Lek formation in sage grouse: The effect of female choice on male territory settlement. Animal Behaviour, 43, 443-450.

Gibson, R. M., \& BACHMan, G. C. (1992). The costs of female choice in a lekking bird. Behavioral Ecology, 3, 300-309.

Gibson, R. M., Bradbury, J. W., \& Vehrencamp, S. L. (1991). Mate choice in lekking sage grouse revisited: The roles of vocal display, female site fidelity, and copying. Behavioral Ecology, 2, 165-180.

Gibson, R. M., \& HöGLund, J. (1992). Copying and sexual selection. Trends in Ecology \& Evolution, 7, 229-231.
Gibson, R. M., \& LANGEN, T. A. (1996). How do animals choose their mates? Trends in Ecology \& Evolution, 11, 468-470.

Godin, J.-G. J., \& BRIGGS, S. E. (1996). Female mate choice under predation risk in the guppy. Animal Behaviour, 51, 117-130.

Goldschmidt, T., BAKKer, T. C., \& Feuth-de Bruijn, E. (1993). Selective copying in mate choice of female sticklebacks. Animal Behaviour, 45, 541-547.

Gong, A., \& Gibson, R. M. (1996). Reversal of a female preference after visual exposure to a predator in the guppy, Poecilia reticulata. Animal Behaviour, 52, 1007-1015.

Gould, J. L., \& Gould, C. G. (1997). Sexual selection: Mate choice and courtship in nature. New York: American Scientific Library.

Grant, J. W. A., \& GREEN, L. D. (1996). Mate copying versus preference for actively courting males by female Japanese medaka (Oryzias latipes). Behavioral Ecology, 7, 165-167.

HEINDL, M., \& WINKLER, H. (2003). Female canaries (Serinus canaria) associate more with males that contrast strongly against the background. Ethology, 109, 259-271.

Hess, E. H., Petrovich, S. B., \& Goodwin, E. B. (1976). Induction of parental behavior in Japanese quail (Coturnix coturnix japonica). Journal of Comparative \& Physiological Psychology, 90, 244-251.

HöGlund, J., \& Alatalo, R. V. (1995). Leks. Princeton, NJ: Princeton University Press.

HoRne, T. J., \& YlÖNEN, H. (1996). Female bank voles (Clethrionomys glareolus) prefer dominant males; but what if there is no choice? Behavioral Ecology \& Sociobiology, 38, 401-405.

Houde, A. E. (1997). Sex, color, and mate choice in guppies. Princeton, NJ: Princeton University Press.

JANETOS, A. C. (1980). Strategies of female mate choice: A theoretical analysis. Behavioral Ecology \& Sociobiology, 7, 107-112.

Jennions, M. D., Blackwell, P. Y., \& Passmore, N. I. (1995). Repeatability of mate choice: The effect of size in the African painted reed frog, Hyperolius marmoratus. Animal Behaviour, 49, 181-186.

JenNions, M. D., \& Petrie, M. (1997). Variation in mate choice and mating preferences: A review of causes and consequences. American Naturalist, 72, 283-327.

KIESTER, R. (1979). Conspecifics as cues: A mechanism for habitat selection in the Panamanian grass anole (Anolis auratus). Behavioral Ecology \& Sociobiology, 5, 323-330.

KirkPATRICK, M., \& DugATKIn, L. A. (1994). Sexual selection and the evolutionary effects of copying mate choice. Behavioral Ecology \& Sociobiology, 34, 443-449.

Kodric-Brown, A., \& Nicoletto,P. F. (2001). Age and experience affect female choice in the guppy (Poecilia reticulata). American Naturalist, 157, 316-323.

KRAAK, S. B. M. (1996). "Copying mate choice": Which phenomena deserve this term? Behavioural Processes, 36, 99-102.

LAfleur, D. L., Lozano, G. A., \& Sclafani, M. (1997). Female matechoice copying in guppies, Poecilia reticulata: A re-evaluation. Animal Behaviour, 54, 579-586.

LALAND, K. N. (1994). Sexual selection with a culturally transmitted mating preference. Theoretical Population Biology, 45, 1-15.

LiLl, A. (1974). Sexual behavior of the lek-forming white-bearded manakin (Manacus manacus trinitatis Hartert). Zeitschrift für Tierpsychologie, 36, 1-36.

Losey, G. S., Stanton, F. G., Telecky, T. M., Tyler, W. A., III, \& THE Zoology 691 Graduate Seminar (1986). Copying others, an evolutionarily stable strategy for mate choice: A model. American Naturalist, 128, 653-664.

Magnhagen, C. (1991). Predation risk as a cost of reproduction. Trends in Ecology \& Evolution, 6, 183-186.

McComb, K., \& Clutton-Brock, T. H. (1999). Is mate choice copying or aggregation responsible for skewed distributions of females on leks? Proceedings of the Royal Society of London: Series B, 255, 13-19.

MEnNill, D. J., RATClifFe, L. M., \& BoAG, P. T. (2002). Female eavesdropping on male song contests in songbirds. Science, 296, 873.

Mills, A. D., Crawford, L. L., Domjan, M., \& FAure, J. M. (1997). The behavior of the Japanese or domestic quail Coturnix japonica. Neuroscience \& Biobehavioral Reviews, 21, 261-281.

Nichols, C. R. (1991). A comparison of the reproductive and behav- 
ioral differences in feral and domestic Japanese quail. Vancouver: University of British Columbia.

Norde LL, S. E., \& VAlone, T. J. (1998). Mate choice copying as public information. Ecology Letters, 1, 74-76.

OPHIR, A., \& GALEF, B. G., JR. (2003a). Female Japanese quail aff iliate with live males that they have seen mate on video. Animal Behaviour, 66, 369-375

OpHIR, A., \& GALEF, B. G., JR. (2003b). Female Japanese quail that "eavesdrop" on fighting males prefer losers to winners. Animal Behaviour, 66, 399-407.

Otter, K., McGregor, P. K., Terry, A. M. R., Burford, F. R. L., Peake, T. M., \& Dabelsteen, T. (1999). Do female great tits (Parus major) assess males by eavesdropping? A field study using interactive song playback. Proceedings of the Royal Society of London: Series $B$, 266, 1305-1309.

Penn, D. J. (2002). The scent of genetic compatibility: Sexual selection and the MHC. Ethology, 108, 1-21.

Persaud, K. N., \& Galef, B. G., JR. (2003). Female Japanese quail aggregate to avoid sexual harassment by conspecific males: A possible cause of conspecific cueing. Animal Behaviour, 65, 89-94.

PruetT-Jones, S. (1992). Independent versus nonindependent mate choice: Do females copy each other? American Naturalist, 140, 1000-1009.

REAL, L. (1991). Search theory and mate choice. II. Mutual interaction, assortative mating, and equilibrium variation in male and female fitness. American Naturalist, 138, 901-917.

REYNoldS, J. D., Gross, M. R., \& CoOMBS, M. J. (1993). Environmental conditions and male morphology determine alternative mating behaviour in Trinidadian guppies. Animal Behaviour, 45, 145-152.

RiebeL, K. (2000). Early exposure leads to repeatable preferences for male song in female zebra finches. Proceedings of the Royal Society of London: Series B, 267, 2553-2558.

Roitberg, B. D., Sircom, J., Roitberg, C. A., Van Alphen, J. J. M. \& MANGEL, M. (1983). Life expectancy and reproduction. Nature, 364, 108

Ruscio, M. G., \& ADKINS-REGAN, E. (2003). Effect of female brooding on male mate choice in Japanese quail, Coturnix japonica. Animal Behaviour, 65, 397-403.

SChlupp, I., MARler, C., \& RYAN, M. J. (1994). Benefit to male sailfin mollies of mating with heterospecific females. Science, 373-374

SCHWAGMEYER, P. L., \& MocK, D. W. (2003). How consistently are good parents good parents? Repeatability of parental care in the house sparrow, Passer domesticus. Ethology, 109, 303-313.

SERVEDIO,M. R., \& KIRKPATRICK, M. (1996). The evolution of mate choice copying by indirect selection. American Naturalist, 148, 848-867.

SHUSTER, S. M., \& WADE, M. J. (1991). Female copying and sexual selection in a marine isopod crustacean Paracerceis sculpta. Animal Behaviour, 41, 1071-1078.

Sirot, E. (2001). Mate-choice copying by females: The advantages of a prudent strategy. Journal of Evolutionary Biology, 14, 418-423.

Slagsvold, T., Hansen, B. T., Johannessen, L. E., \& LifJeld, J. T. (2002). Mate choice and imprinting in birds studied by cross-fostering in the wild. Proceedings of the Royal Society of London: Series B, 269, 1449-1455.

Slagsvold, T., \& VilJugrein, H. (1999). Mate choice copying versus preference for actively displaying males by female pied flycatchers. Animal Behaviour, 57, 679-686.

STÖHR, S. (1998). Evolution of mate choice copying: A dynamic model. Animal Behaviour, 55, 893-903.

Sullivan, M. S. (1994). Mate choice as an information gathering process under a time constraint: Implications for behavior and signal design. Animal Behaviour, 47, 141-151.

THORNHILL, R. (1976). Sexual selection and nuptial feeding behavior in Bittacus apicalis (Insecta: Mecoptera). American Naturalist, 110, 529-548

Trivers, R. L. (1972). Parental investment and sexual selection. In B. Campbell (Ed.), Sexual selection and the descent of man 18711971 (pp. 136-179). Chicago: Aldine.

VinNEDGE, B., \& VERRELL, P. (1998). Variance in male mating success and female choice for persuasive courtship displays. Animal Behaviour, 56, 443-448.

WAdE, M. J., \& PRuetT-Jones, S. G. (1990). Female copying increases the variance in male mating success. Proceedings of the National Academy of Science, 87, 5749-5753.

WAGNER, R. H., \& DANChIN, E. (2003). Conspecific copying: A general mechanism of social aggregation. Animal Behaviour, 65, 405408.

WAGNER, W. E., JR. (1998). Measuring female mating preferences. Animal Behaviour, 55, 1029-1042.

WeST, M. J., \& KING, A. P. (1988). Female visual displays affect the development of male song in the cowbird. Nature, 334, 244-246.

West-EBerhard, M. J. (1983). Sexual selection, social competition, and speciation. Quarterly Review of Biology, 58, 155-183.

Westneat, D. F., Walters, A., McCarthy, T. M., Hatch, M. I., \& HeIn, W. K. (2000). Alternative mechanisms of nonindependent mate choice. Animal Behaviour, 59, 467-476.

White, D. J., \& GALEF, B. G., JR. (1999a). Affiliative preferences are stable and predict mate choices in both sexes of Japanese quail, $\mathrm{Co}$ turnix japonica. Animal Behaviour, 58, 865-871.

White, D. J., \& GaleF, B. G., JR. (1999b). Mate-choice copying and conspecific cueing in Japanese quail, Coturnix coturnix japonica. Animal Behaviour, 57, 465-473.

White, D. J., \& GAlef, B. G., JR. (1999c). Social effects on mate choices of male Japanese quail, Coturnix japonica. Animal Behaviour, 57, 1005-1012.

White, D. J., \& GAlef, B. G., JR. (2000a). Culture in quail: Social influences on mate choices of female Coturnix japonica. Animal Behaviour, 59, 975-979.

White, D. J., \& Galef, B. G., JR. (2000b). Differences between the sexes in the direction and duration of response to seeing a potential sex partner mate with another. Animal Behaviour, 59, 1235-1240.

White, D. J., King, A. P., \& West, M. J. (2002). Facultative development of courtship and communication skills in juvenile male cowbirds, Molothrus ater. Behavioral Ecology, 23, 487-496.

Wiegman, D. D., Real, L. A., Capone, T. A., \& Ellner, S. (1996). Some distinguishing features of models of search behavior and mate choice. American Naturalist, 147, 188-204.

WiTTE, K., \& RYAN, M. [J.] (1998). Male body length influences matechoice copying in the sailfin molly Poecilia latipinna. Behavioral Ecology, 9, 534-539. 